\begin{tabular}{|c|c|}
\hline $\begin{array}{c}\text { European Association for the } \\
\text { Development of Renewable Energies, Environment } \\
\text { and Power Quality (EA4EPQ) }\end{array}$ & $\begin{array}{c}\text { International Conference on Renewable Energies and Power Quality } \\
\text { (ICREPQ'12) }\end{array}$ \\
Santiago de Compostela (Spain), 28th to 30th March, 2012
\end{tabular}

\title{
Voltage-induced stresses during Low Voltage Ride Through (LVRT) in the drive train of wind turbines with DFIG
}

\author{
Dr.-Ing. Jan Wenske ${ }^{1}$, Prof. i.R. Dr.-Ing. habil. Ulrich Beckert ${ }^{2}$ \\ ${ }^{1}$ Fraunhofer Institut für Windenergie und Energiesystemtechnik \\ IWES \\ Am Seedeich 45, 27572 Bremerhaven (Germany) \\ Phone/Fax number:+0049 471 14290-400, e-mail: jan.wenske@iwes.fraunhofer.de \\ ${ }^{2}$ Institut für Elektrotechnik, TU Bergakademie Freiberg \\ Lessingstraße 45, 09599 Freiberg (Germany) \\ Phone/Fax number:+0049 3731-392929, e-mail: Ulrich.Beckert@et.tu-freiberg.de
}

\begin{abstract}
Nowadays stochastic occurrence of main grid disturbances (LVRT, FRT) leads to high level vibrational excitation of the drive train during operation of wind turbines.

Regardless of the drivetrain design as a direct, hybrid or multistage geared one in this case high mechanical and electrical stresses should be expected. This voltage-induced stress resulting from the generator-load input function, in which the air gap torque of the generator changes with high dynamic rates. The momentum is sufficient to excite any significant natural frequencies of the above-mentioned power train variants and of all mechanically coupled systems, such as the rotor blades, main frames, nacelle and tower structures.

The effects within the drivetrain are shown by simulation by means of a physically discretized torsional oscillator model of a typical multi-megawatt wind turbine with a conventional multistage gearbox and fast running DFIG drivetrain design. A general method for a controller setting will be discussed to handle these abormal grid side conditions. Using FOC for the DFIG-converter system electrical stress will be limited by the rotor current control.
\end{abstract}

\section{Key words}

Doubly-Fed Induction Generator (DFIG), Low voltage ride through (LVRT), Fault ride through (FRT), drivetrain oscillation, wind turbine drivetrain, field oriented vectorcontrol (FOC)

\section{Introduction}

For analysis of system behaviour in case of grid-side voltage dips systemic differences, with respect to the electromechanical drivetrain concepts, with direct impact on drivetrain loads, can be observed. This contribution focuses on DFIG drivetrain configurations. Regardless of this, in a "worst-case scenario" the turbine is loaded with rated torque within the drive train before a FRT grid event in a time range of $100 \mathrm{~ms}$ to $1000 \mathrm{~ms}$ occurs and relieves the generator side almost completely. The reason for this is the virtually unchanged grid-side system operation at nominal current according international grid codes, but a lack of active power output to the grid.

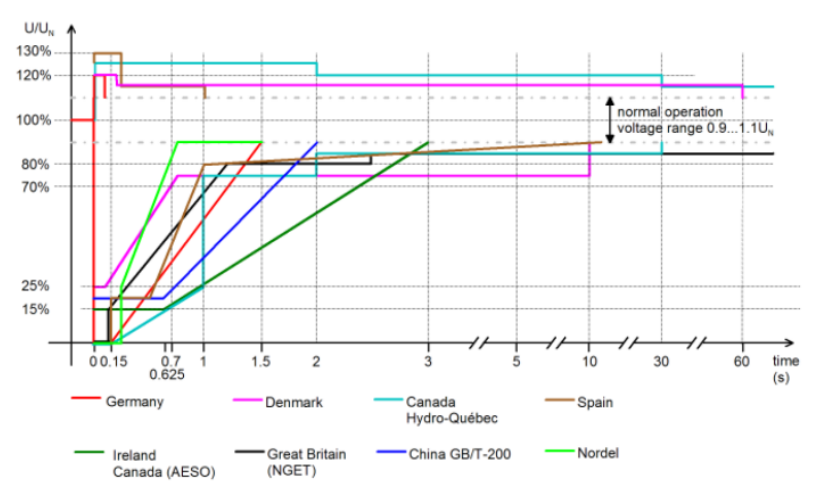

Fig. 1. Examples of different international LVRT and HVRT specifications for transmission lines (grid codes)

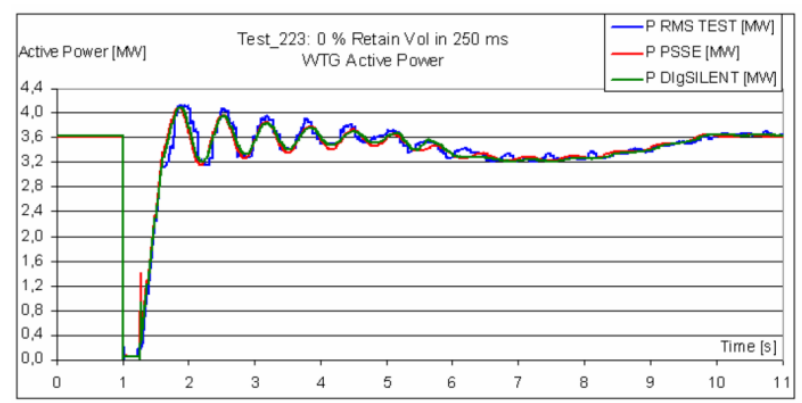

Fig. 2. Active power output of a 3.6 MW wind turbines during and after an FRT-Grid Event [2]

For obtaining a unit certificate and for the confirmation of conformity with the locally valid "grid-codes", field tests must been carried out. The figures 2 and 3 show a comparison of measurement and simulation results using different software tools [2]. 


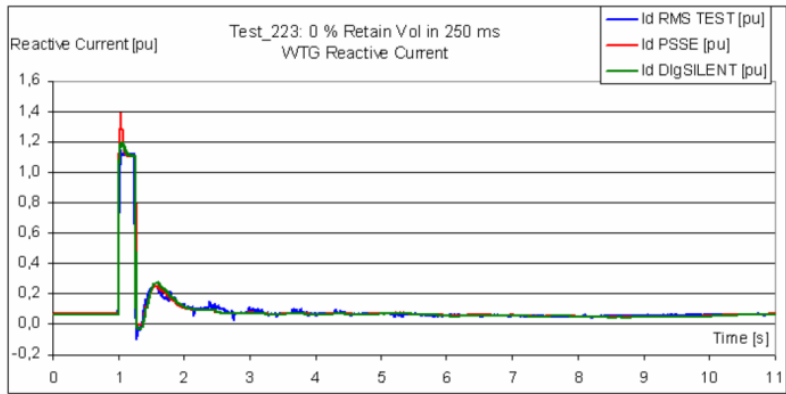

Fig. 3. Reactive power output of a $3.6 \mathrm{MW}$ wind turbines during and after an FRT-Grid Event [2]

While the grid fault the system feed as required reactive power in the amount of nominal current (including tolerance) into the grid, the active power output is reduced to near zero. After the fault clearing the system after a transient phase is in the nominal operating again. As mentioned above, the excitation via the air gap torque results in vibrations of the drive train components within all mechanical degrees of freedom.

For analysis of the mechanical drivetrain-stress a reduced order model is used to describe the dominating system behaviour. This seems physically justified by the exclusive excitation by the air gap torque.

\section{Drive train modeling}

\section{Mechanical drive train subsystem}

The afore preliminary mentioned modeling of the mechanical drive train system as a torsional chain oscillator is sufficiently accurate. Only for the detailed design of the drive train working with multi-body and flex-body models as well as FEM calculations and modeling are essential. In this contribution the chain of oscillators is modeled in a conventional way. The relevant equations and the corresponding signal flow chard is shown in figure 4 , here examplary as a reduced 4-mass oscillator, all equations are formulated in the p.u. system.

Equations for the equivalent interia and the shaft modeling of the torsional oscillator chain:

$$
\begin{aligned}
& m_{W 12}-m_{i}=T_{J 1} \frac{d \omega_{J 1}}{d t} \text { (1) } m_{R o t o r}-m_{W 34}=T_{J 4} \frac{d \omega_{J 4}}{d t} \\
& m_{W 23}-m_{W 12}=T_{J 2} \frac{d \omega_{J 2}}{d t} \quad m_{W 34}-m_{W 23}=T_{J 3} \frac{d \omega_{J 3}}{d t} \\
& \text { with } \quad T_{J i}=J_{i} \frac{\omega_{B}}{M_{B}} \quad i=1, \ldots, 4 \\
& m_{W j}=\frac{1}{T_{W j}} \int \Delta \omega_{J j} d t+K_{W j} \Delta \omega_{J j} \\
& j=12,23,34 \\
& \Delta \omega_{J j}=\omega_{J(i+1)}-\omega_{J i} \\
& \text { with } \\
& T_{W i}=\frac{1}{c_{\varphi j}} \\
& K_{W j}=d_{\varphi j} \frac{\omega_{B}}{M_{B}}
\end{aligned}
$$

$$
m_{\text {Rotor }}=\frac{P_{W \text { ind }}}{M_{B} \omega_{\text {Rotor }} i_{\text {gear }}}
$$

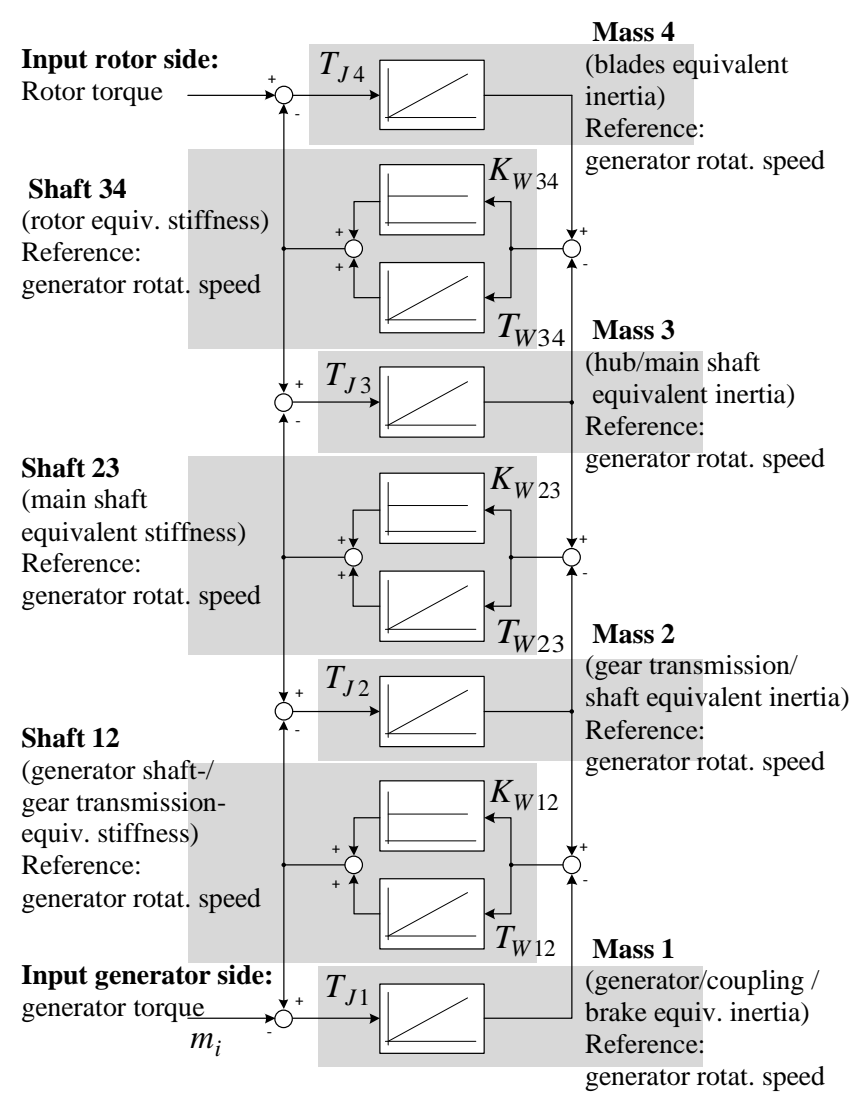

Fig. 4. Signal flow chard of the mechanical drive train (reduced order 4-mass-torsional oscillator model)

Table I. Example data for a 5MW turbine

\begin{tabular}{|c|c|c|c|c|c|c|}
\hline $\begin{array}{c}\text { Inertia } \\
J_{1}\end{array}$ & $\begin{array}{c}\text { Shaft } \\
c_{\varphi 12}\end{array}$ & $\begin{array}{c}\text { Inertia } \\
J_{2}\end{array}$ & $\begin{array}{c}\text { Shaft } \\
c_{\varphi 23}\end{array}$ & $\begin{array}{c}\text { Inertia } \\
J_{3}\end{array}$ & $\begin{array}{c}\text { Shaft } \\
c_{\varphi 34}\end{array}$ & $\begin{array}{c}\text { Inertia } \\
J_{4}\end{array}$ \\
\hline $\begin{array}{c}595,9 \\
\mathrm{kgm}^{2}\end{array}$ & & 48,1 & & 12,7 & & 4115 \\
& $\mathrm{kgm}^{2}$ & & $\mathrm{kgm}^{2}$ & & $\mathrm{kgm}^{2}$ \\
\hline & $\begin{array}{c}2,7 * 10^{6} \mathrm{~N} \\
\mathrm{~m} / \mathrm{rad}\end{array}$ & & $\begin{array}{c}2,34 * 10^{6} \\
\mathrm{Nm} / \mathrm{rad}\end{array}$ & & $\begin{array}{c}0,63 * 10^{5} \\
\mathrm{Nm} / \mathrm{rad}\end{array}$ & \\
\hline
\end{tabular}

DFIG subsystem

Within the following DFIG equations all variables and parameters are normalized by means of the usual reference values (index $B$ ). As a result we obtain the formulation of all equations in a normalized p.u. system. (Index 1: DFIG stator value; Index 2: DFIG rotor value)

$$
\begin{array}{ll}
f_{B}=f_{1 n} & t_{B}=\frac{1}{\omega_{B}}=\frac{1}{2 \pi f_{1 n}} \\
\omega_{B}=\omega_{1 n}=2 \pi f_{1 n} & R_{B}=X_{B}=\frac{U_{B}}{I_{B}} \\
U_{B}=\sqrt{2} U_{1 n} & \Psi_{B}=\frac{U_{B}}{\omega_{B}}=\frac{\sqrt{2} U_{1 n}}{2 \pi f_{1 n}} \\
I_{B}=\sqrt{2} I_{1 n} & M_{B}=\frac{P_{B}}{\omega_{B} / p}=\frac{3 p U_{1 n} I_{1 n}}{2 \pi f_{1 n}}
\end{array}
$$

It is very common for general considerations, regarding analysis and controller synthesis, to rely on the wellknown mathematical fundamental frequency model of the doubly-fed induction machine in the stator flux space vector oriented coordinate system $x, j y[1],[3],[4]$. 

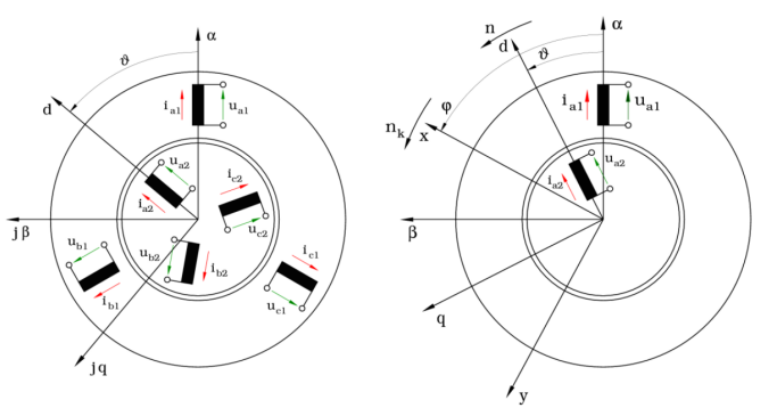

Fig. 5. Equivalent circuit and coordinate systems of the DFIG

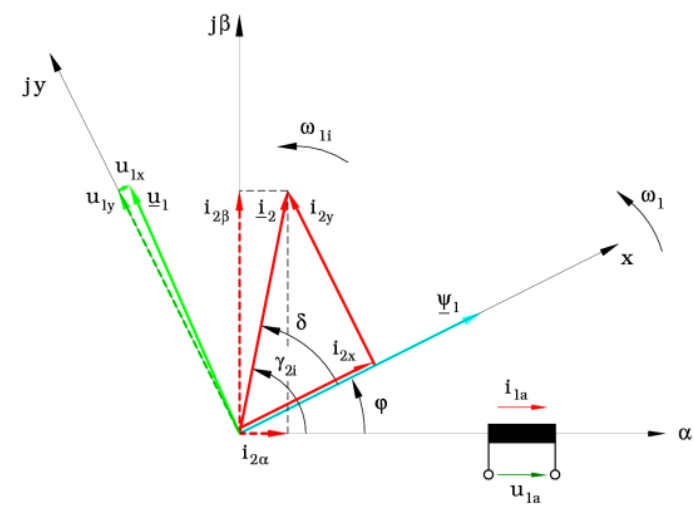

Fig. 6. Component analysis with the DFIG space vectors diagram

$$
\begin{aligned}
& \frac{d \underline{\psi}_{1}}{d t}=\underline{u}_{1}-R_{1} \underline{i}_{1}-j n_{k} \underline{\psi}_{1} \\
& \frac{d \underline{\psi}_{2}}{d t}=\underline{u}_{2}-R_{2} \underline{i}_{2}-j\left(n_{k}-n\right) \underline{\psi}_{2} \\
& \underline{\psi}_{1}=X_{1} \underline{i}_{1}+X_{h} \underline{i}_{2} \\
& \underline{\psi}_{2}=X_{h} \underline{i}_{1}+X_{2} \underline{i}_{2} \\
& m_{i}=\underline{\psi}_{1} \times \underline{i}_{1}=\frac{X_{h}}{X_{2}}\left(\underline{\psi}_{2} \times \underline{i}_{1}\right)
\end{aligned}
$$

This specific control technique of the generator is generally known as field oriented control (FOC). In this case we choose the rotating (rotating with $\omega=1$ ) stator flux space vector $\psi_{1}$ oriented coordinate system. As a result of the control synthesis, the active and the reactive power will be completely decoupled from each other and can be controlled independently from the speed. Thereby the FOC basically consists of two two-loops cascade structures. The $\mathrm{x}$ and $\mathrm{y}$ components of rotor currents are subordinated under the loops of the active and reactive power control of DFIG stator, see Figure 6.

The modeling of the controlled system within the stator flux linkage space vector $\psi_{1}$ field-oriented coordinate system $x, j y$, taking into account these definitions,

$$
\begin{array}{lll}
n_{k}=\omega_{1} & (15) & \vartheta=\omega t+\vartheta_{0} \\
\underline{\psi}_{1}=\psi_{1 x} & (17) & \psi_{1 y}=0
\end{array}
$$

leads to the following equations for the two axes of the doubly-fed induction generator under field-oriented rotor current control by means of voltage converters:

$$
\begin{aligned}
& u_{1 \alpha}=\hat{u}_{1} \cos \left(t+\varphi_{u 1}\right) \\
& u_{1 x}=u_{1 \alpha} \cos (\varphi)+u_{1 \beta} \sin (\varphi)
\end{aligned}
$$

$$
\begin{aligned}
& \frac{d \psi_{1 x}}{d t}=u_{1 x}-R_{1} i_{1 x} \\
& \frac{d \psi_{2 x}}{d t}=u_{2 x}-R_{2} i_{2 x}+\left(\omega_{1}-\omega\right) \psi_{2 y} \\
& m_{i}=\underline{\psi}_{1} \times \underline{i}_{1}=\frac{X_{h}}{X_{1}} \psi_{1 x} i_{2 y} \\
& i_{1 x}=\frac{1}{\sigma X_{1}}\left(\psi_{1 x}-\frac{X_{h}}{X_{2}} \psi_{2 x}\right) \\
& i_{2 x}=\frac{1}{\sigma X_{2}}\left(\psi_{2 x}-\frac{X_{h}}{X_{1}} \psi_{1 x}\right) \quad \text { with } \\
& \sigma=1-\frac{X_{h}^{2}}{X_{1} X_{2}}=\text { total leakage coefficient } \\
& u_{1 \beta}=\hat{u}_{1} \sin \left(t+\varphi_{u 1}\right) \\
& u_{1 y}=-u_{1 \alpha} \sin (\varphi)+u_{1 \beta} \cos (\varphi) \\
& \frac{d \varphi}{d t}=\omega_{1}=\frac{1}{\psi_{1 x}}\left(u_{1 y}-R_{1} i_{1 y}\right) \\
& \frac{d \psi_{2 y}}{d t}=u_{2 y}-R_{2} i_{2 y}-\left(\omega_{1}-\omega\right) \psi_{2 x} \\
& i_{1 y}=-\frac{1}{\sigma X_{1}} \frac{X_{h}}{X_{2}} \psi_{2 y} \\
& i_{2 y}=\frac{1}{\sigma X_{2}} \psi_{2 y}
\end{aligned}
$$

DFIG in steady state operation

In stationary mode all originally alternating values, which have been transformed into the reference coordinate system, appear as direct values.

$$
\text { With } \quad \frac{d \underline{\psi}_{1}}{d t}=0 \quad(33) \text { at } \quad \omega_{1}=\text { konst. } \approx 1
$$

for the DFIG apply the following equations

$$
\begin{aligned}
& u_{1 x}=R_{1} i_{1 x} \\
& i_{1 x}=\frac{1}{X_{1}} \psi_{1 x}-\frac{X_{h}}{X_{1}} i_{2 x} \\
& u_{1 y}=R_{1} i_{1 y}+\psi_{1 x} \\
& i_{1 y}=-\frac{X_{h}}{X_{1}} i_{2 y}
\end{aligned}
$$

for regular operation near the nominal voltage $\left(u_{1} \approx\right.$ 1) and under the following additional approximations

$$
u_{1 x}<<u_{1 y} \approx u_{1} \quad(38) \quad \psi_{1 x} \approx u_{1 y} \approx u_{1}
$$

, i.e. the space vector of stator flux linkage and the stator voltage are nearly perpendicular to each other and have (normalized) about the same size. Taking into account these simplifications we obtain the following relationships for the independent active and reactive power consumption or generation of the DFIG on its stator side (grid side):

$$
\begin{aligned}
& p_{1}=\operatorname{Re}\left[\underline{u}_{1} \cdot \underline{i}_{1}^{*}\right] \approx u_{1} i_{1 y} \\
& =-\frac{X_{h}}{X_{1}} u_{1} i_{2 y} \quad \text { (40) } p_{1} \sim i_{2 y} \\
& q_{1}=\operatorname{Im}\left[\underline{u}_{1} \cdot \underline{i}_{1}^{*}\right] \approx u_{1} i_{1 x} \\
& =\frac{u_{1}^{2}}{X_{1}}-\frac{X_{h}}{X_{1}} u_{1} i_{2 x}(42) \quad q_{1} \sim i_{2 x}
\end{aligned}
$$


Voltage Converter for DFIG (back-to-back topology)

For these considerations the grid-side of the converter mathematical model description should be made in ACline fixed coordinate system [5]. However the following description on the generator side, bases on the respective coordinate system of the generator model (see above).

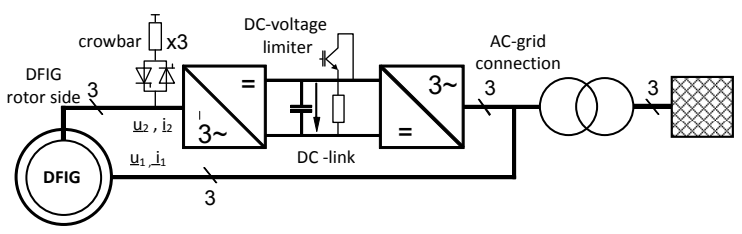

Fig. 7. Schematic of a DFIG-converter system for wind turbines

The converter, which is the actuators for the AC-side output voltages, is described as first order delay model. (without Index: output value, with Index *: input value):

$u_{2 x}=\frac{1}{T_{U} \cdot s+1} u_{2 x}^{*} \quad(44) \quad u_{2 y}=\frac{1}{T_{U} \cdot s+1} u_{2 y}^{*}$

Be simplified for the further considerations, all partial converter delays will be summed and occur in the equivalent time constant $T_{U}$. The converters intermediate circuit (DC-link) including an electric short-term storage $C_{Z w k}$. as well as a voltage limiter unit (refer to figure 7 ). Using the principle of conversion of energy an essential model for power electronics voltage level within the DC intermediate circuit (DC-link voltage $u_{D C}$ ) can be created. The so-called crowbar acts as a surge limiter for the DFIG rotor side and the corresponding converter to protect this subsystem during abnormal condition (e.g. FRT).

\section{Controller synthesis \& settings for DFIG}

General DFIG control structure for wind turbines By means of the already presented mathematical DFIGmodel and the measured values of the rotor and stator side phase currents, the instantaneous values for the active $p$ and reactive power $q$ and the coordinate transformations angle $(\varphi-\vartheta)$, necessary for the FOC of the DFIG, will calculated. As usual in industrial drive applications all four controller within the cascaded structure are assumed as PIcontrollers. The control structure, shown in figure 8 , allows a decoupled and independend active and reactive power control at the stator side, i.e. the grid side of the wind turbine.

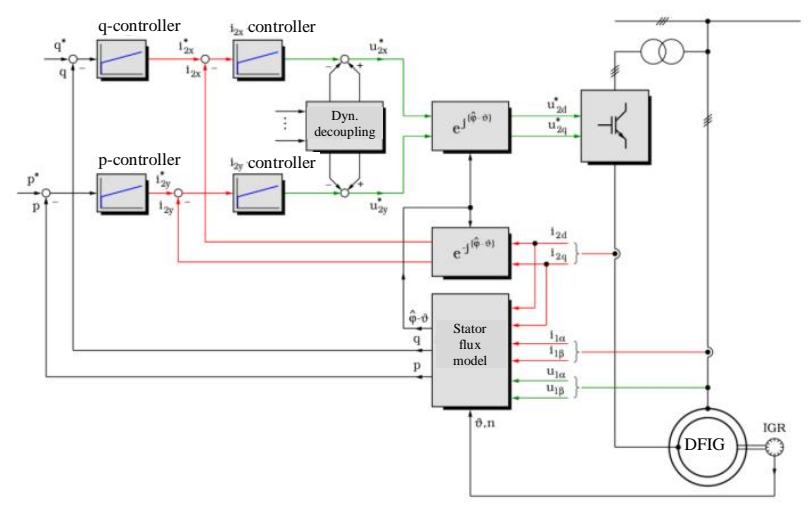

Fig. 8. FOC control structure for wind turbine application
Dynamic decoupling and Rotor-side current contol loop For the setting of the rotor current control loops, the knowledge of their controlled paths (for each axis within the $x, y$ coordination system) are necessary. By eliminating the rotor flux and the stator current the following expressions (46) and (47) are obtained.

$$
\begin{aligned}
u_{2 x}= & R_{0} i_{2 x}+\sigma X_{2} \frac{d i_{2 x}}{d t} \\
& -\frac{X_{h}}{X_{1}} \frac{R_{1}}{X_{1}} \psi_{1 x}-\sigma X_{2} \omega_{2} i_{2 y}+\frac{X_{h}}{X_{1}} u_{1 x} \\
u_{2 y}= & R_{0} i_{2 y}+\sigma X_{2} \frac{d i_{2 y}}{d t} \\
& -\frac{X_{h}}{X_{1}} n \psi_{1 x}+\sigma X_{2} \omega_{2} i_{2 x}+\frac{X_{h}}{X_{1}} u_{1 y}
\end{aligned}
$$

in which is

$$
R_{0}=\left(\frac{X_{h}}{X_{1}}\right)^{2} R_{1}+R_{2}(48) \quad \omega_{2}=\omega_{1}-\omega
$$

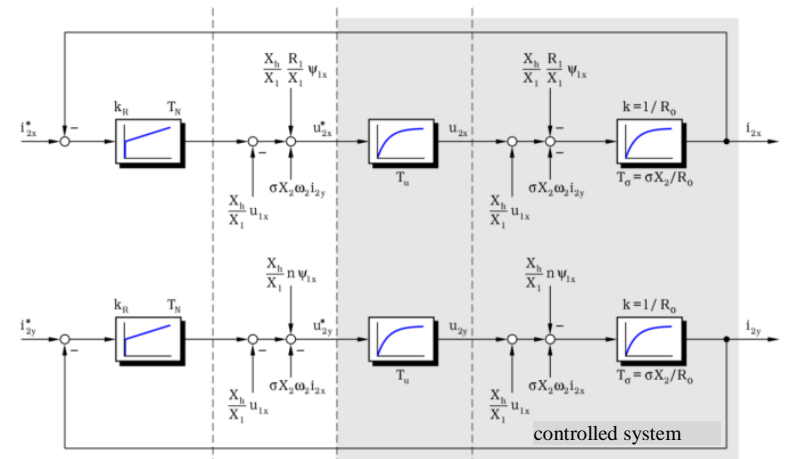

Fig. 9. Rotor-side current control with dynamic decoupling

The cross-coupling terms within Eqn. (46) and (47) will be compensated, like it is common for field-oriented control of induction motor drives by intrusion of the corresponding quantities with the opposite sign. As a result the meshed control system decompose into two separated rotor current control loops have the same structure, each for one current component within DFIG rotor.

$u_{2 x}=R_{0} i_{2 x}+\sigma X_{2} \frac{d i_{2 x}}{d t}$
$u_{2 y}=R_{0} i_{2 y}+\sigma X_{2} \frac{d i_{2 y}}{d t}$

Transfer function description ( $s=$ laplace operator) (52)

$$
F_{s}(p)=\frac{i_{2 x}(s)}{u_{2 x}^{*}(s)}=\frac{i_{2 y}(s)}{u_{2 y}^{*}(s)}=\frac{1 / R_{0}}{\left(1+s T_{u}\right)\left(1+s \sigma X_{2} / R_{0}\right)}
$$

Thereby the time constant $T_{U}$ of the first order delay term in Eqn. (52) represents the converter model introduced earlier in Eqn. (44) and (45). The controller parameter settings are chosen in accordance to the optimum magnitude criterium.

(equivalent closed loop damping coefficient of $1 / \sqrt{2}$ )

$$
T_{N}=\sigma X_{2} / R_{0} \quad \text { (53) } \quad k_{R}=\frac{1}{2} \frac{\sigma X_{2}}{T_{u}}
$$


Active \& reactive power control loops (DFIG stator-side) For analysis and optimization of the superposed active and reactive power control loop, the reference reaction of the magnitude optimal adjusted current control loops is emulated by a first order delay element with the double delay time $T_{U}$ of the converter.

$$
F_{i}(s)=\frac{i_{2 x}(s)}{i_{2 x}^{*}(s)}=\frac{i_{2 y}(s)}{i_{2 y}^{*}(s)}=\frac{1}{1+s 2 T_{u}}
$$

According to the equations (40) and (42) the gain of the corresponding transfer functions can be described as:

$$
\begin{aligned}
& F_{p}(s)=\frac{p_{1}(s)}{i_{2 y}(s)}=-\frac{X_{h}}{X_{1}} u_{1} \\
& F_{q}(s)=\frac{q_{1}(s)}{i_{2 x}(s)}=-\frac{X_{h}}{X_{1}} u_{1} \\
& i_{\mu}=\frac{u_{1}}{X_{1}} \quad \text { DFIG stator magnetizing current }
\end{aligned}
$$

If we consider that the actual values calculated are smoothed by a first order filter (59), finally the transfer functions of the control loops for the active and reactive power on the DFIG grid-side described by the following equation (65).

$$
\begin{gathered}
F_{F}(p)=\frac{1}{1+s T_{F}} \quad \text { filter transfer function } \quad(59,60) \\
F_{S p, q}(s)=\frac{p_{1}(s)}{i_{2 y}^{*}(s)}=\frac{q_{1}(s)}{i_{2 x}^{*}(s)}=\frac{-\frac{X_{h}}{X_{1}} u_{1}}{\left(1+s T_{F}\right)\left(1+s 2 T_{u}\right)}
\end{gathered}
$$

It is also remarkable, that the magnetizing current has a character of a disturbance in the reactive power control loop of the DFIG. Since it is almost constant during normal operation, i.e. with rigid grid voltage, the term does not need to be compensated by a dynamic decoupling.

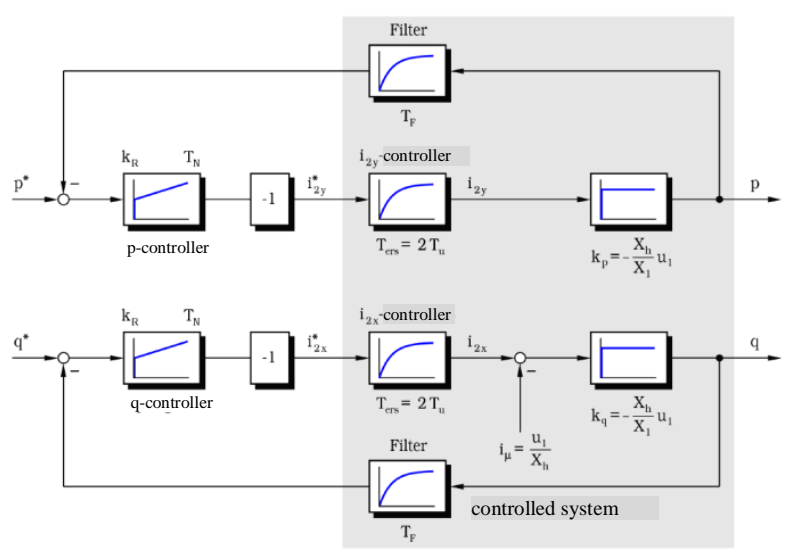

Fig. 10. Signal flow chart of the active and reactive power control loops for the DFIG and converter

Even the settings of the power controller parameter in principle are tuned according to the optimum magnitude criterium. But unlike to the current controllers design no overshoot of instantaneous power values during setpoint changes are allowed. This requires a closed-loop relative damping coefficient greater than or equal to 1 for the power controller loop design, while for the DFIG rotor current control loops a coefficient of 0.7 has been strived.

$$
\mathrm{T}_{\mathrm{N}, \mathrm{q}}=\mathrm{T}_{\mathrm{F}} \quad \text { (61) } \quad \mathrm{k}_{\mathrm{Rp}, \mathrm{q}}=\frac{\mathrm{T}_{\mathrm{F}}}{4 \mathrm{D}^{2} \frac{\mathrm{X}_{\mathrm{h}}}{\mathrm{X}_{1}} \mathrm{u}_{1} \mathrm{~T}_{\mathrm{u}}}
$$

The parameter settings for the PI-controller based on the following definition of the transfer function:

$$
\mathrm{F}(\mathrm{s})=\mathrm{k}_{\mathrm{R}} \frac{1+\mathrm{s} \mathrm{T}_{\mathrm{N}}}{\mathrm{s} \mathrm{T}_{\mathrm{N}}}
$$

\section{Simulation results}

Refering to the mathematical model descriptions and the controler synthesis some simulation results of the operation case symmetrical FRT (special case of LVRT) are presented. Thereby it was assumed that the line voltage phasor drops from $\mathrm{u}_{1}=1.0(100 \%$ of rated voltage) to $u_{1}=0.05$ (5\% of rated voltage) for a duration of $t_{\text {drop }}=10 \times T_{\text {line }}(200 \mathrm{~ms})$ and then recovers again, with defined slew-rates (refer to figure 11). The conducted simulations are based on the 5.4-MW generator DASAA WE-8030-6U of VEM Sachsenwerk.

Table II. Technical data generator DASAA WE-8030-6U

\begin{tabular}{|l|cc|}
\hline $5400 \mathrm{~kW}$ & $5684 \mathrm{kVA}$ & $($ at $\cos \varphi=+0.95)$ \\
\hline $1170 \mathrm{~min}^{-1}$ & $670 \ldots 1330 \mathrm{~min}^{-1}$ operating speed \\
\hline $950 \mathrm{~V}$ & $3019 \mathrm{~A}$ & $50 \mathrm{~Hz}$ (DFIG stator) \\
\hline $\begin{array}{l}1920 \mathrm{~V} \\
\text { (at standstill) }\end{array}$ & $1696 \mathrm{~A}$ & (DFIG rotor) \\
\hline
\end{tabular}

In general the mechanical part of the drive-train is modeled and simulated according figure 4 . For comparison simulations with consideration of the immanent existing transmission gears backlash (located between mass 2 and 3) were performed. Within this representative turbine drive train configuration no significant additional mechanical stresses appear in the drive-train. It has also been assumed that during the duration of the line voltage dip, due to the large time constant of the pitch control of 2-4s [3], [4], the turbine driving torque remains constant. Furthermore the turbine operates at its rated point. Figures 11 and 12 show the time response of some system variables of the DFIG during the LVRT-event (without consideration of mechanical backlash).

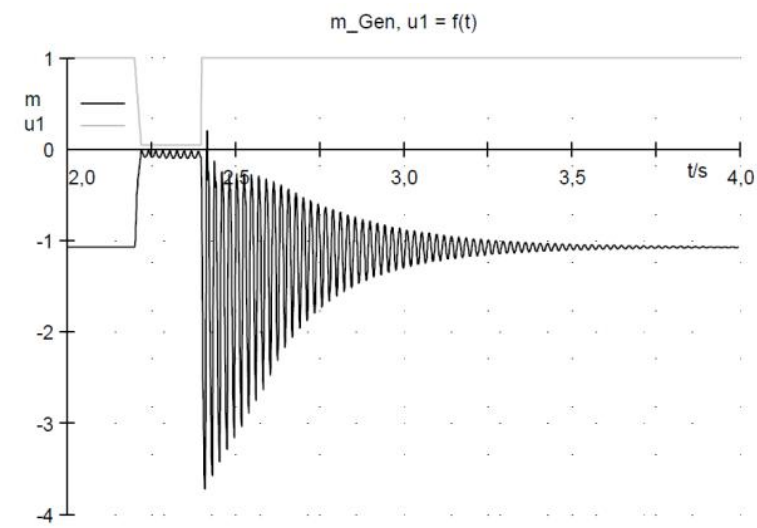

Fig. 11. DFIG field oriented controlled by the voltage converter during a sym. line voltage dip (LVRT event) 


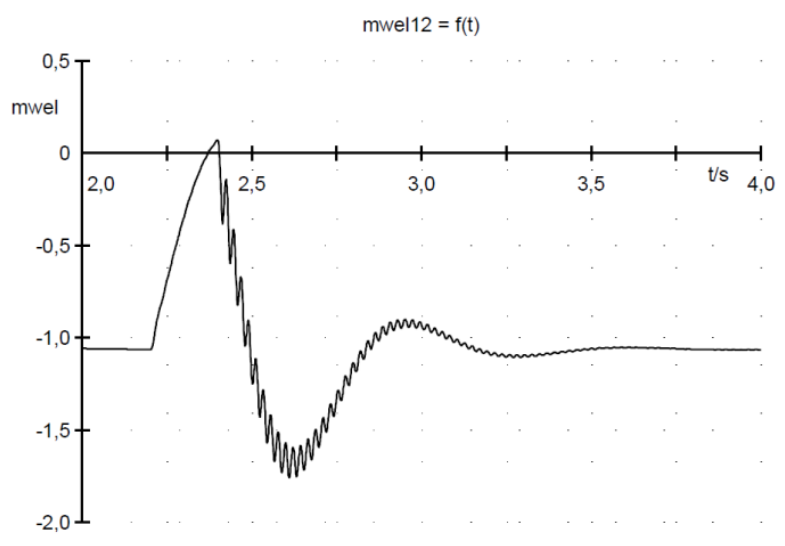

Fig. 12. Corresponding generator shaft torque during sym. line voltage dip (LVRT event)

All system variables are shown in normalized form. Reference values for normalization are the rated torque, the rated power and amplitude of the rated voltage and current of the generator. The main advantage of normalization is, that all system variables only vary in a narrow range, which is characteristical for them and regardless of the rated power of the DFIG. Thus the simulation results have a more general character.

The air gap torque of the generator $m_{i}$ runs during the voltage dip and even after voltage recovery with damped oscillation of line frequency and up to three times rated torque. Due to the inertia-distribution within the drive-train the magnitude of the generator shaft torque reaches little more than one and a half times rated torque, thus the safety coupling is not tripped (min. triggering level 2 times rated torque). The system therefore remains in the normal operating range during this symmetrical FRT grid event.

The shaft torque time responses are clearly dominated by the lowest natural drive-train frequency with maximum peak torques slightly over 1.7 rated torque, even under worst case condition with high dynamic voltage recovery and mechanical backlash consideration (figures 4. \& 5).

$$
f_{01}=1.64 \mathrm{~Hz},\left(f_{02}=34,6 \mathrm{~Hz}, f_{03}=78,4 \mathrm{~Hz}\right)
$$

Further analysis shows that the peak load depends primarily on rise time of the voltage recovery. For this purpose the simulation results presented here have been assumed with the highest dynamic (refer to grid-codes requirements at figure 1). Under the assumption, that after the voltage dip the magnitude of the voltages rises during $t_{\text {rise }}=2 \mathrm{~ms}$ linearly from $\hat{u}_{1}=0.05$ to $\hat{u}_{1}=1.0$.

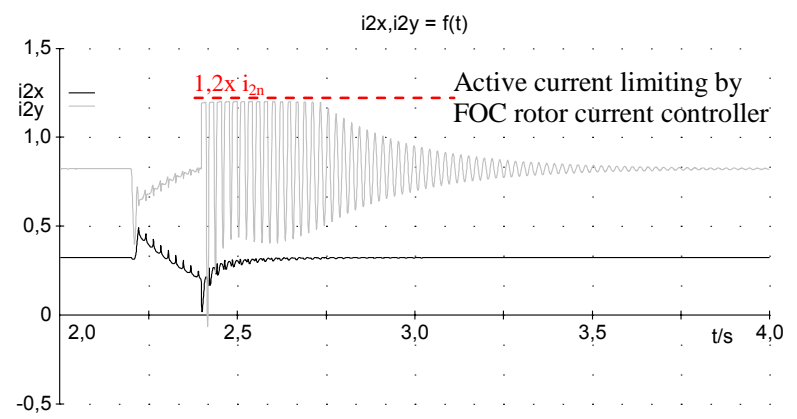

Fig. 13. Active rotor current limiting by the rotor-side converter during LVRT-condition (no triggering of protection systems, like crowbar or internal DC-voltage limiter, ref. to figure 7)

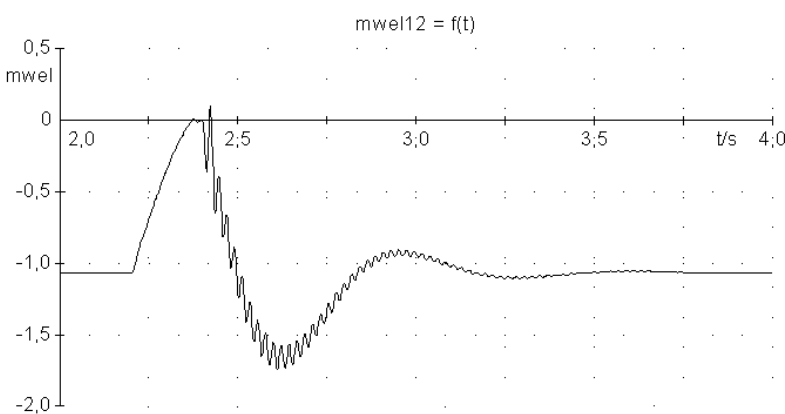

Fig. 14. Generator shaft torque (with mechanical backlash)

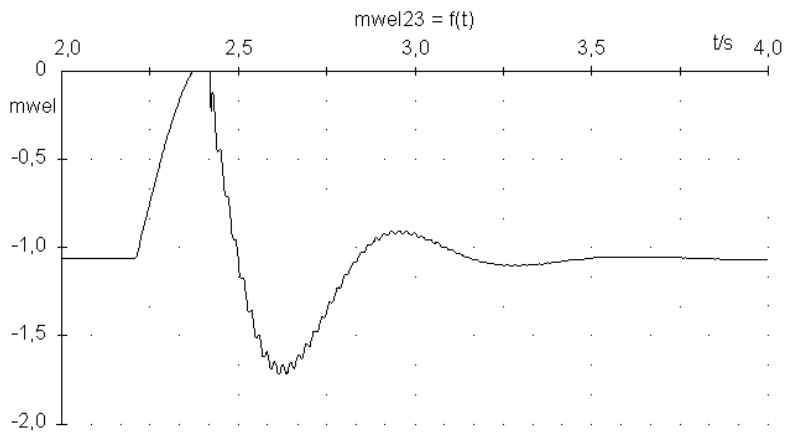

Fig. 15. Turbine main shaft torque (with mechanical backlash)

\section{Conclusion}

Some of the very special technical challenges in use of DFIGs within wind turbine drive train were discussed. Using high end vector control, the impact of grid disturbances like LVRT-events on the electrical as well as on the mechanical drive train system can be managed in a proper way by using standard PI-controller. Under these aspects the from a cost perspective still very attractive DFIG configuration within wind turbines has a future even with increasing grid code requirements. For active oscillation damping within the drive-train, especially under consideration of mechanical backlashes, standard PIcontrol loops are not sufficient. This challenge can be solved by implementing more effective structures like state space controls [6].

\section{References}

[1] Beckert, U.; Doppeltgespeiste Asynchronmaschine als drehzahlvariabler Windenergiegenerator und ihre feldorientierte Regelung; Forschungsbericht Institut für Elektrotechnik der TU Bergakademie Freiberg 2010

[2] Gonnsen, A.; Latest developments in Voltage Ride Through (VRT) technology for electronic systems in wind turbine concepts, International conference E/E Systems for Wind Turbines, Mai 2011, Bremen

[3] Slootweg, J.G., Polinder, H., Kling, W.L.; Dynamic Modelling of a Wind Turbine with Doubly Fed Induction Generator; 2001 IEEE

[4] Conroy, J.F., Watson, R.; Low-voltage ride-through of a full converter wind turbine with permanent magnet generator; IET, 2007, pp.182-189

[5] Wenske, J.; Elektronische Synchronmaschine mit aktivem Dämpferkreis zur Energiekonditionierung in elektrischen Versorgungssystemen, Dissertation 1999, TU Clausthal

[6] Thomsen, S., Fuchs, F.W.; Conventional and State Space Control for active Damping of mechanical vibrations in speed drive systems with backlash; Christian-AlbrechtsUniversität zu Kiel, Kiel, Germany 2008 